\title{
Exposure assessment of heavy metals pollution enriched in core sediment samples of river Nile, Aswan, Egypt
}

\author{
E.M. Fawzy ${ }^{1}$, M.N. Rashed ${ }^{1}$, M.E. Soltan ${ }^{2,1 *}$ \\ ${ }^{1}$ Chemistry Department, Faculty of Science,Aswan Univeristy,Aswan 81528, Egypt \\ ${ }^{2}$ Faculty of Science and Arts at Al-Rass, Al-Rass 51921, Qassim University, Qassim, \\ Saudi Arabia
}

Received: 7 October 2016

Accepted: 5 March 2017

Published online: 18 March 2017

\begin{abstract}
The river Nile is a dominating physical feature of the north- eastern part of the African continent, covering areas exhibiting varieties and contrasts in topography, climate vegetation and people. So, in this study, we estimated the contamination of the Nile sediment with some major and trace heavy metals in core samples which can cause some undesirable health effects. Concentrations of all elements shows that the maximum enrichment is found in the top subsamples, while the most elements shows low contents in the lower layer reflecting the impact of human activity on the sediment contents. Different normalizing methods were used, i.e. geoaccumulation ( $\left.\mathrm{I}_{\mathrm{geo}}\right)$ and enrichment factor (EF), for the influence of the natural variability in sediment mineralogy and to assess whether the concentrations observed in surface sediment represent background or contaminated levels. The study has also shown the importance of different sediment characteristics in spatial distribution of heavy metals in the sediments of river Nile. To protect the ecological system of river Nile watershed, industrial mining and agricultural activities along river stream should to be strictly regulated.
\end{abstract}

Keywords: core, sediment, metals, Nile, Egypt

\section{Introduction}

Metals are natural components of ecosystems and many of them are essential for the organisms. Only when their contents exceed certain values could they become contaminants to the environments (Gao et al. 2014). Excessive amount of trace elements is a serious environmental problem in many ecosystems around the world. Most of them are essential and very important such as copper, zinc, manganese and iron. These metals are cofactors in many enzymes and play an important role in many physiological functions of man and animals (Koh and Judson 1986). Some of them, such as copper, nickel, manganese, chromium and iron are essential in very low concentration for the survival of all forms of life (Watson 2001). Only when they are presented in higher quantities, can these, like the heavy metals lead, cadmium be toxic also in very low concentrations and cause metabolic anomalies (Hernandez-Avila et al. 2003). Lead occurs naturally from the decomposition of parent rocks and may

\footnotetext{
* Corresponding author: M.E.Soltan

e-mail: 3481@qu.edu.sa; mesoltan@hotmail.com
} 
accumulate from anthropogenic sources, including traffic exhaust, lead-zinc smelters, dumps and other sites receiving industrial and household lead, e.g., paints and batteries (Mulligan et al. 2001 ).

In recent years, studies about possible health and ecological effects of accumulated toxic metals in sediments have been published (Krishnamurti et al. 1995; Gismera et al. 2004; Franca et al. 2005; Chatteriee et al. 2007 ; Shokrzadeh and Saeedi Saravi 2010; Landre et al. 2011; Wang et al. 2012; Fawzy et al. 2012; Li et al. 2013; Fu et al. 2014; Wang et al. 2015; Chen et al. 2016 and El Azhari et al. 2016). Metals entering into aquatic systems are usually rapidly transported into sediments ( Gu et al. 2016). However, with changing environmental conditions, e.g. pH and Eh; they can be released and represent a secondary contamination source, affecting ecosystems of nearby seas and estuaries (Kalantzi et al. 2013). Consequently, sediments are both carriers of metals and potential pollution sources in aquatic systems ( $\mathrm{Gu}$ and Lin 2016). Because heavy metals are not biodegradable, certain concentrations of them can adversely influence organisms and natural environments and can threaten human health by entering the food chain (Wang et al. 2013).

It is well established that trace metals may be introduced to sedimentary environments by both natural processes (e.g. weathering and erosion) and human activities within the catchments' area. Since trace metals from natural and anthropogenic sources accumulate together, it is difficult to determine the contribution of the sedimentary metal load from these two sources. Metals released to the environment from various natural and anthropogenic sources accumulate in the sediments, providing a record of metal emissions over time (Landre et al. 2011). Different methods have been proposed to distinguish the anthropogenic sources of HMs in sediments from natural sources including statistical methods, geochemical indices, and isotope tracing techniques (Han et al. 2015a; Bing et al. 2016; Chen et al. 2016).

The anthropogenic inputs mainly came from industrial activities of the tributary rivers such as heavy metal mining and smelting, and agricultural practices such as fertilizing and pesticide consumption (Wang et al. 2012). $\mathrm{Zn}, \mathrm{Pb}, \mathrm{Cd}$ and As mainly originated from mining wastewater and industrial wastewater, but $\mathrm{Cr}$ and $\mathrm{Cu}$ mainly derived from natural erosion and nonpoint agricultural sources (Li et al. 2013). Recognizing the pollution characteristics of trace metals in river sediments and targeting their potential sources are of key importance for proposing effective strategies to protect watershed ecosystem health (Chen et al. 2016).

Sediments are regarded as a mixture of inorganic material; however, concentrations of trace metals in sediments largely depend on inorganic material resulting from physical and chemical weathering of rocks and soils in the catchments' area. This inorganic material is predominantly composed of less weathering primary silicate minerals such as quartz, feldspars and micas, as well as secondary minerals formed during weathering of primary minerals e.g. clay minerals (Verca and Dolenec 2005).

River sediments provide an archive of environmental change within the river region; therefore, have been used across the world in order to study natural environmental change or human impacts. Distribution of trace elements in the river sediments not only reflects pollution from atmospheric deposition, but also reveals the past land-use histories (Oldfield et al. 2003). Detailed work has been carried out on the distribution of heavy metals with depth in sediments cores ( Yu et al. 2001; Whelan III et al. 2005; Vreca and Dolenec 2005; Shi et al. 2010). Core sediments have been proved to be an excellent tool for establishing the effects of anthropogenic and natural processes on depositional environments (Harikumar and Nasir 2010), and they can be used to study the pollution history of aquatic ecosystems (Vallius 2014; Veerasingam et al. 2015).

The river Nile is one of the longest rivers in the world, measuring 6,670 km from the headwaters of the Kagera river in Rwanda to the shores of the Mediterranean in Egypt with a surface area about $2,978,000 \mathrm{~km}^{2}$. The river Nile has given Egypt a fertility that led to its ancient agricultural civilization and helped in developing this civilization in peace and stability. It well known from historical sources 
Fawzy et al.

that Ancient Egypt, in the Greek and Roman periods, mud were used as antiseptic cataplasms to cure skin, stomach and intestinal aliments, as well as for cosmetic purposes (Carretero 2002; Vreca and Dolenec 2005).

This study aims to show the impact of agricultural, industrial and population activities and tourist boats on sediment contamination by the metallic elements in different locations at Aswan city, Egypt using core samples, and comparing the concentrations of elements in the different layers to see their source, whereas the release of this elements to water bodies under different factors ( for example, decreasing of $\mathrm{pH}$, increasing of Eh and organic matters ) leads to dangerous on aquatic organisms and human health .On the other hand, the study points out the need to preserve waterways from pollution and the need for waste treatment, whatever their source.

\section{Materials and methods}

\subsection{Samples and Reagents}

Sediment core samples were collected using a polyethylene corer down to a depth of about 90 $\mathrm{cm}$ from five locations along the river Nile (Aswan city, Egypt), named West Sohiel ,West Aswan, Bahareef, El-Aakab and El-Akaba (Fig. 1). At each location core sample of $90 \mathrm{~cm}$ depth was sampled from the river bank, sectioned into 1- surficial sediment horizon $(0-30 \mathrm{~cm}), 2$ - upper sediment horizon $(30-50 \mathrm{~cm}), 3-$ middle sediment horizon $(50-70 \mathrm{~cm})$ and 4- lower sediment horizon $(70-90 \mathrm{~cm})$.

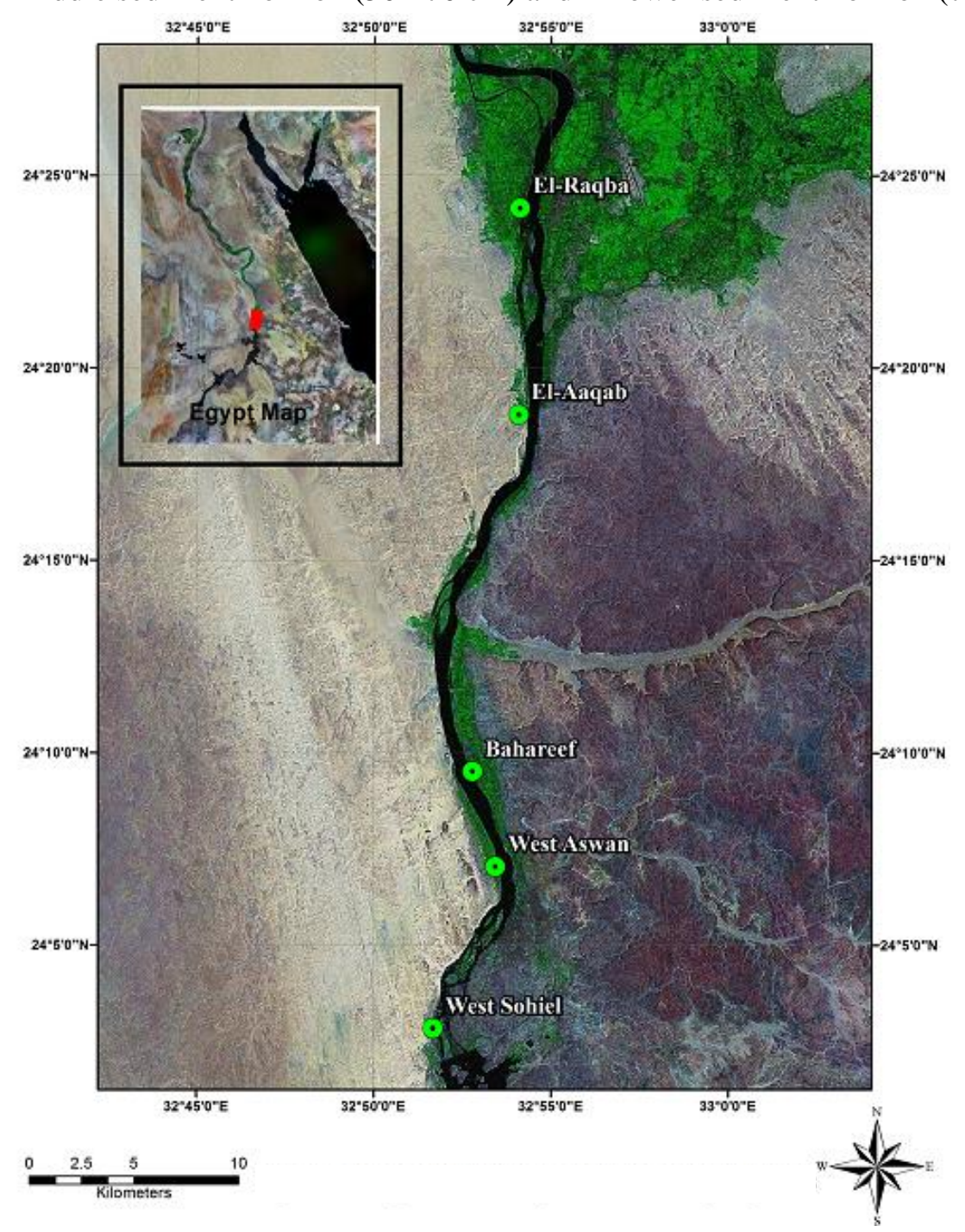

Fig. 1 Map of the study area and sampling sites. 
All glass and plastic wares were soaked in $10 \%$ nitric acid overnight and rinsed thoroughly with deionized water before use. For quality control, reagent blanks, replicates were incorporated in the analysis to direct contamination and assess precision. The standard addition calibration method and extraction blanks were employed to avoid interferences in the measurements. All standard for calibration were prepared for adequate analytical grade salts in the various reagent solutions.

\subsection{Sediment Analysis}

The sediment samples were air dried, homogenized and stored for subsequent analysis. The $\mathrm{pH}$, conductivity and salinity were measured in 1: 2.5 suspension of sample: bidistilled water using pHmeter (Orion Research, Model SA520, U.S.A.) and conductivity meter (HANNA Instruments, HI 8033 Italy), respectively. Total carbonate and phosphate contents were determined by a volumetric method and spectrophotometrically at $\lambda=690 \mathrm{~nm}$ using molybdenum blue method, respectively (APHA 1992). In the choice of extracting reagents, particular emphasis was placed on the selectivity, suitability and extracting efficiency of each leaching solution. The extraction method that is the most informative for environmental purposes is the total element content. Each a homogenized mixed core sample was digested by sequential total acids attack using concentrated $\mathrm{HNO}_{3}, \mathrm{HF}$ and $\mathrm{HCl}(1: 1: 1)$ mixture (Tessier et al. 1979; Belzile et al. 1989; Li et al. 1995; Whelan III et al. 2005; Janaki et al. 2007). In each digested sample, the total metal concentrations ( $\mathrm{Pb}, \mathrm{Zn}, \mathrm{Cd}, \mathrm{Cr}, \mathrm{Fe}, \mathrm{Ni}, \mathrm{Cu}, \mathrm{Mn}, \mathrm{Co}, \mathrm{Al}, \mathrm{Ca}$, and $\mathrm{Mg}$ ) were determined by atomic absorption and flame emission ( $\mathrm{K}$ and $\mathrm{Na}$ ) spectrophotometer.

\subsection{Assessment of Sediment Quality}

The simple approach to the normalization of geochemical data is to compare the total metal concentrations of surface sediment with concentrations characteristics of natural background levels or anthropogenically uncontamination, for assessing Sediment quality, can also be calculated by using the so-called index of geoaccumulation ( $\mathrm{I}_{\mathrm{geo}}$ ) proposed by Müller (1979) and defined as: $\mathrm{I}_{\mathrm{geo}}=\log _{2} \mathrm{Cn} / 1.5 \mathrm{Bn}$.

Where $\mathrm{Cn}$ is the measured concentration of the metal $\{\mathrm{n}\}$ in the sediment, $\mathrm{Bn}$ represents the geochemical background concentration in average shale (Turekian and Wedepohl 1961) of the metal $\{\mathrm{n}\}$ and 1.5 is the background matrix correlation factor due to lithogenic effects. The index of geoaccumulation consists of seven grades, whereby the highest grad (6) reflects 100-fold enrichment above background values (Müller 1969, 1979; Vreca and Dolenec 2005). The assessment of sediment samples according to this index is summarized in Tab. 2. In order to evaluate the data in more detail, the enrichment factors (Efs) are calculated as follows:

$\mathrm{EF}=(\mathrm{X} / \mathrm{Y})$ sample/ (X/Y) background (Szefer et al. 1996; Vreca and Dolenec 2005).

Where $\mathrm{X}$ is the concentration of potentially enriched metal and $\mathrm{Y}$ is the concentration of the reference metal (Middlenton and Grant 1990), the validity of such an enrichment factor varies with the value used for the background levels (Kersten and Smedes 2002), aluminum is used here as the reference element.

\section{Results and discussion}

Sediment in rivers not only plays an important role influencing the pollution of river water but also can be used to record the history of river pollution. Thus, sediment acts as both carriers and potential sources of contaminants in an aquatic environment (Yu et al. 2001).

\subsection{Elements Distribution}

Heavy metal transportation and distribution within the study area are important for the assessment of long term environmental impacts of the metal contamination. The results expressed as 
total metals concentrations. Generally, the horizontal variation in the element concentrations presents a complex picture as it is affected by many factors, including variations in the industrial effluents influx, intensity of erosion during periods of high water discharge and agitation of the bottom sediments by river traffic and navigation.

Some of chemical Characteristics for the samples collected from different sediment depths are recorded in Tab. 1. For surface sediment $(0-30 \mathrm{~cm})$ in all locations, the content of all elements show that the maximum enrichment is found in the top subsamples. Indeed, most elements show lower contents with depth in all the cores (Fig. 2), the increase in heavy metals in the upper layers of the core samples reflects the combined effects of discharge of fishery boats and trade ships (Fawzy 2000; Moalla et al. 2006).

Calmano et al. (1993) have pointed out that metals in the surface of bottom sediments would be released into the water phase by physico-chemical processes; this means any change in environmental conditions in the system may render the remobilization of metals from sediments. Chen et al. (2017) studied the effects of elevated phosphorus in water on the release of heavy metals in sediments and stated that the Excessive phosphorus $(\mathrm{P})$ input plays an important role on the release of heavy metals in sediments under the eutrophic environment. Nowadays, heavy metals are frequently detected in the environment including both bed sediments and water columns and have gradually become a major concern worldwide due to anthropogenic activities. As shown in Tab. 2 and Fig. 2, most of metals levels specially cadmium (Fig. 2a) are decreased with depth. There are no significant distribution trends for heavy metals between the some sampling locations (Tab. 2).

Tab. 1 Some of chemical characteristics of sediment core samples.

\begin{tabular}{cccccccccccc}
\hline $\begin{array}{c}\text { Sample } \\
\text { Depth }\end{array}$ & \multicolumn{2}{c}{ Mean } & Range & \multicolumn{2}{c}{ Mean } & \multicolumn{1}{c}{ Range } & \multicolumn{2}{c}{ Mean Range } & \multicolumn{2}{c}{ Mean } & \multicolumn{2}{c}{ Range } & \multicolumn{2}{c}{$\begin{array}{c}\text { Mean } \\
\text { Resphates }\left(\mathbf{m g g}^{-1}\right) \\
\text { Range }\end{array}$} \\
\hline Surface & 7.85 & $7.6-8.4$ & 1509.2 & $898-2724$ & 0.6 & $0.42-0.66$ & 147.4 & $137-162.5$ & 9.6 & $5.5-17.5$ \\
$30 \mathrm{~cm}$ & 7.4 & $7-8.1$ & 6924 & $3240-9020$ & 2.6 & $2.14-4.44$ & 118.6 & $112-137.5$ & 8.3 & $7-12.5$ \\
$50 \mathrm{~cm}$ & 7.9 & $7.28-8.78$ & 5782 & $1746-21880$ & 2.86 & $0.8-10.98$ & 141 & $137-150$ & 6.6 & $5.75-8.0$ \\
$70 \mathrm{~cm}$ & 8 & $7.31-8.78$ & 1256.8 & $864-1444$ & 0.56 & $0.4-0.7$ & 138.7 & $125-162.5$ & 10.1 & $5.5-24.5$ \\
$90 \mathrm{~cm}$ & 7.9 & $7.69-8.52$ & 1456.2 & $396-3244$ & 0.9 & $0.56-1.62$ & 140 & $125-150$ & 9.95 & $8-13.25$ \\
\hline
\end{tabular}

Tab. 2 Levels of metal concentrations in the sediment samples $\left(\mu \mathrm{gg}^{-1}\right)$ and I-geo class.

\begin{tabular}{ccccc}
\hline & Surface sediment & $\begin{array}{c}\text { Average shale } \\
\text { (standard) }\end{array}$ & * I-geo class & Designation of sediment \\
\hline $\mathrm{Pb}$ & 0.64 & 20 & 0 & uncontaminated \\
$\mathrm{Zn}$ & 1.35 & 95 & 0 & uncontaminated \\
$\mathrm{Co}$ & 0.86 & 19 & 0 & uncontaminated \\
$\mathrm{Cr}$ & 2 & 90 & 0 & uncontaminated \\
$\mathrm{Fe}$ & 672 & 46.700 & 0 & uncontaminated \\
$\mathrm{Ni}$ & 0.82 & 68 & 0 & uncontaminated \\
$\mathrm{Cu}$ & 0.75 & 45 & 0 & uncontaminated \\
$\mathrm{Mn}$ & 10.9 & 850 & 0 & uncontaminated \\
$\mathrm{Cd}$ & 0.1 & 0.3 & 0 & uncontaminated \\
$\mathrm{Ca}$ & 17,000 & 2.200 & 1 & unpolluted to moderately \\
& & & & polluted \\
$\mathrm{Mg}$ & 29,500 & 1.500 & 1 & unpolluted to moderately \\
& & & 0 & polluted \\
$\mathrm{Na}$ & 17,500 & 10.000 & 0 & uncontaminated \\
$\mathrm{K}$ & 44,60 & 2.700 & & uncontaminated \\
\hline
\end{tabular}

"I-geo: Geoaccumulation-Index Class. 
A portion of measured metals content was from lithogenic origin, because the sediment in this region consists of fine granite particles from igneous rock present in the main stream and sides of the river Nile. In addition, highest metals accumulation of sediment at West Aswan is due to anthropogenic sources resulting from agricultural, industrial and domestic discharge. The mean metal concentrations are below the shale average values (Tab. 3).

Tab. 3 Different metals content measured at various depths in sediment core samples.

\begin{tabular}{|c|c|c|c|c|c|c|c|c|c|c|c|c|c|c|}
\hline \multirow{3}{*}{$\begin{array}{c}\text { West Aswan } \\
1\end{array}$} & $\mathbf{P b}$ & $\mathbf{Z n}$ & Co & $\mathrm{Cr}$ & $\mathbf{F e}$ & $\mathrm{Ni}$ & $\mathrm{Cu}$ & Mn & Cd & Al & $\mathbf{C a}$ & Mg & $\mathrm{Na}$ & K \\
\hline & \multicolumn{10}{|c|}{$\left(\mu g^{-1}\right)$} & \multicolumn{4}{|c|}{$\left(\mathrm{mgg}^{-1}\right)$} \\
\hline & 0.7 & 1.27 & 0.8 & 2 & 740 & 0.8 & 0.74 & 9.3 & 0.12 & 600 & 20 & 30.4 & 15 & 4.6 \\
\hline 2 & 0.7 & 1.22 & 0.6 & 2 & 690 & 0.8 & 0.72 & 8.8 & 0.11 & 600 & 17.5 & 27.4 & 14.5 & 4.5 \\
\hline 3 & 0.6 & 1.16 & 0.6 & 2 & 690 & 0.6 & 0.68 & 8.2 & 0.08 & 600 & 15 & 25.8 & 14.4 & 4.5 \\
\hline 4 & 0.6 & 1.15 & 0.6 & 2 & 640 & 0.6 & 0.63 & 8.2 & 0.07 & 600 & 15 & 22.8 & 14.3 & 4.3 \\
\hline 5 & 0.6 & 1.1 & 0.5 & 2 & 600 & 0.07 & 0.61 & 8.1 & 0.02 & 500 & 15 & 15.2 & 12.4 & 4.2 \\
\hline \multicolumn{15}{|l|}{ West Sohiel } \\
\hline 1 & 0.7 & 1.26 & 0.7 & 2 & 650 & 0.7 & 0.74 & 10.3 & 0.11 & 700 & 20 & 27.4 & 16.7 & 4.5 \\
\hline 2 & 0.6 & 1.14 & 0.7 & 2 & 650 & 0.6 & 0.72 & 9.2 & 0.07 & 600 & 15 & 25.8 & 14 & 4.5 \\
\hline 3 & 0.6 & 1.08 & 0.6 & 2 & 650 & 0.6 & 0.66 & 7.9 & 0.06 & 600 & 15 & 24.3 & 13.2 & 4.3 \\
\hline 4 & 0.5 & 10.3 & 0.6 & 1 & 630 & 0.6 & 0.66 & 7.6 & 0.06 & 600 & 15 & 22.8 & 12.9 & 4.2 \\
\hline 5 & 0.4 & 0.95 & 0.3 & 1 & 540 & 0.5 & 0.58 & 6.5 & 0.04 & 500 & 12.5 & 19.8 & 12.8 & 4.0 \\
\hline \multicolumn{15}{|l|}{ Bahareef } \\
\hline 1 & 0.6 & 1.14 & 0.9 & 2 & 690 & 0.8 & 0.76 & 11.3 & 0.06 & 700 & 15 & 28.9 & 13.9 & 4.4 \\
\hline 2 & 0.5 & 1.06 & 0.9 & 2 & 670 & 0.6 & 0.68 & 10.3 & 0.06 & 600 & 15 & 27.4 & 13.6 & 4.3 \\
\hline 3 & 0.5 & 1.02 & 0.7 & 2 & 610 & 0.5 & 0.66 & 10.3 & 0.06 & 600 & 15 & 24.3 & 13.6 & 4.3 \\
\hline 4 & 0.4 & 0.95 & 0.6 & 2 & 610 & 0.5 & 0.66 & 9.0 & 0.05 & 600 & 12.5 & 24.3 & 13.3 & 4.3 \\
\hline 5 & 0.4 & 0.95 & 0.5 & 2 & 600 & 0.5 & 0.64 & 8.9 & 0.05 & 600 & 7.5 & 19 & 12.4 & 4.2 \\
\hline \multicolumn{15}{|l|}{ El-Aaqub } \\
\hline 1 & 0.6 & 1.77 & 1 & 2 & 640 & 0.9 & 0.76 & 11.8 & 0.11 & 800 & 15 & 30.4 & 25.2 & 4.4 \\
\hline 2 & 0.6 & 1.33 & 0.9 & 2 & 640 & 0.8 & 0.75 & 10.4 & 0.1 & 700 & 12.5 & 30.4 & 16.3 & 4.3 \\
\hline 3 & 0.6 & 1.24 & 0.8 & 2 & 640 & 0.7 & 0.67 & 10.1 & 0.08 & 600 & 10 & 25.8 & 16.5 & 4.3 \\
\hline 4 & 0.5 & 1.23 & 0.7 & 2 & 610 & 0.6 & 0.65 & 9.2 & 0.06 & 600 & 10 & 24.3 & 15.2 & 4.2 \\
\hline 5 & 0.4 & 0.95 & 0.3 & 2 & 590 & 0.5 & 0.60 & 7.5 & 0.05 & 600 & 10 & 24 & 13.2 & 4 \\
\hline \multicolumn{15}{|l|}{ El-Raqba } \\
\hline 1 & 0.6 & 1.33 & 0.9 & 2 & 640 & 0.9 & 0.75 & 11.8 & 0.1 & 800 & 15 & 30.4 & 16.5 & 4.4 \\
\hline 2 & 0.6 & 1.24 & 0.8 & 2 & 640 & 0.7 & 0.67 & 10.4 & 0.08 & 600 & 12.5 & 25.8 & 16.3 & 4.3 \\
\hline 3 & 0.5 & 1.23 & 0.7 & 2 & 640 & 0.6 & 0.65 & 10.1 & 0.06 & 600 & 10 & 24.3 & 15.2 & 4.2 \\
\hline 4 & 0.5 & 1.06 & 0.7 & 2 & 610 & 0.5 & 0.62 & 9.2 & 0.05 & 600 & 10 & 24 & 13.2 & 4.2 \\
\hline 5 & 0.4 & 0.95 & 0.3 & 2 & 590 & 0.5 & 0.60 & 7.5 & 0.04 & 600 & 7 & 24 & 12.5 & 4.0 \\
\hline
\end{tabular}

(1) Surface sediment, (2) 0-30 cm, (3) $30-50 \mathrm{~cm}$, (4) $50-70 \mathrm{~cm}$, (5) $70-90 \mathrm{~cm}$

\subsection{Spatial Distribution}

Manganese concentrations in sediment core samples, in general, lower than the average abundance of this element in shale standard $(<850 \mathrm{ppm})$ and show slight and almost similar variation in the river Nile sediments, this suggests that physicochemical and biological properties (Tab. 1) of the Nile sediments ( $\mathrm{pH}$; Carbonate, Phosphate concentration, redox potential, etc.) are major importance in controlling the bioavailability concentrations the element. Decrease in metal content, however, in the deep, consistent with the fact that, this redox sensitive element derived from the early diagenesis of the sediment, is believed to have been oxidized and flocculated by the oxygen-rich Nile water (Balkis and 
Çağatay 2001). The relatively high iron concentration is due to abundance of magnetite $\left(\mathrm{Fe}_{2} \mathrm{O}_{3}\right)$ and ilmenite $\left(\mathrm{FeTiO}_{3}\right)$ minerals in the river Nile sediments (Fawzy 2000).

A comparison of the results of total, $\mathrm{Pb}, \mathrm{Cu}, \mathrm{Zn}, \mathrm{Ni}$, and $\mathrm{Cr}$ in core samples display smaller values compared to those of the average shale (Tab. 3). These date supported the Merry et al. (1983) and Lin (2002) contention that surface horizons accumulate $\mathrm{Pb}$. Specific mechanisms that could complex $\mathrm{Pb}$ are sedimentation, adsorption by clay minerals, and phosphate bonding. Furthermore, chelation by organic matter is especially in retaining $\mathrm{Pb}$.

Vertical variation of $\mathrm{Ca}$ and $\mathrm{Mg}$ showed almost high abundance in surface sediments (Fig. 2c), suggests that concentrations of these metals are mainly associated with the carbonate phases (Tab. 1) and they have similar transport mechanisms. The slight variation in $\mathrm{Ca}$ and $\mathrm{Mg}$ concentrations reflect the endogenic enrichment of these two elements in Nile sediments. High concentration of carbonates (Tab. 1) could be attributed to the abundance of molluscs and calcareous tubeworms (Bernasconi and Stanley 1994). Most of these shell fragments are composed of calcium carbonates, in addition to the geological composition of surrounding rocks. Soltan (2006) studied the sediment quality of the river Nile and the distribution of some trace elements in the bulk sediments of the river. He concluded that the alkaline $\mathrm{pH}$ values (Tab. 1) of the Nile sediments reduce the release of the metals from sediments to water.

Nickel contents were very similar in all sampling sites (Tab. 2), while $\mathrm{Ca}, \mathrm{Mg}, \mathrm{Fe}$ and $\mathrm{Al}$ were higher. Cadmium levels were surprisingly high in West Aswan (Tab. 2). It is important to observe that the West Aswan is as enriched in heavy metals as compared with the other locations, suggest that these contaminants are generated from fishery boats, discharges of trade ships and direct erosion of igneous rocks by the effect of water movement.

The higher cadmium content in the surface sediment than the other horizons (in all locations, Tab. 2) indicates that the Cd present in these so-called unpolluted soils is of anthropogenic origin (Andersen et al. 2002). The vertical distribution patterns for most studied metals show that, the levels are generally low and do not indicate any significant anthropogenic input, thus are derived predominantly from natural sources lithologic material.

Looking at the mean heavy metal concentrations at different depths within the sediment profiles of river Nile are presented in Fig. 2, the metal contents in surface sediments are generally higher than those in deeper layer. However, the difference between top sediment and bottom sediment layer is not statistically significant for many metals due to the various distribution patterns in individual cores (Tab. 4). The metal concentrations in the rest of the core are very similar (Fig. 2). The metal enrichment at the surface of the profile may reflect the impacts of contaminant inputs from recent industrial development around the Nile (Fig. 3). The river gully area reflects the high water flow and dynamic environment. The metal distribution in the profile can be affected by many factors including the river input, sediment properties and dredging activities (Winkels et al. 1993; Li et al. 2000).

The obtained data of metals concentrations were compared with the data which reported by Fawzy (2000), where it appeared an increase in concentrations of some measured metals in our results.. This is due to the accelerated growth of industry, manufactories and industrial plants have been established near or on the Nile banks. These plants have discharge their industrial waste for several years into the Nile. In addition, most of the population is densely concentrated in the Nile Valley and this has a direct effect on the quality of the river Nile water. Also in the last twenty years, the Nile has been used extensively in Nile cruises with about 300 ships operating between Luxor and Aswan. Thus, not only does Nile water satisfy domestic and industrial needs, it also provides transportation, hydroelectric power, a means of sewage and waste disposal, fish for food and forms of recreation. Therefore, the quality of river Nile water generally reflects the range of human activities within the catchments' area especially in the absence of the annual flushing out by the floodwater. 
Environment, Earth and Ecology Vol. 1 No. 1 (2017), 46-60 Fawzy et al.

DOI: $10.24051 /$ eee/69290

Tab. 4 Descriptive statistics for measured metals concentration $\left(\mu \mathrm{gg}^{-1}\right)$ of core samples in different depths.

\begin{tabular}{|c|c|c|c|c|c|}
\hline & Surface & $30 \mathrm{~cm}$ & $50 \mathrm{~cm}$ & $70 \mathrm{~cm}$ & $90 \mathrm{~cm}$ \\
\hline \multicolumn{6}{|c|}{$\mathbf{P b}\left(\mu \mathrm{gg}^{-1}\right)$} \\
\hline Range & $0.6-0.7$ & $0.5-0.7$ & $0.5-0.6$ & $0.4-0.6$ & $0.4-0.6$ \\
\hline SE & 0.02 & 0.03 & 0.02 & 0.003 & 0.04 \\
\hline SD & 0.055 & 0.07 & 0.05 & 0.07 & 0.09 \\
\hline \multicolumn{6}{|c|}{$\mathbf{Z n}\left(\mu \mathrm{gg}^{-1}\right)$} \\
\hline Range & $1.14-1.77$ & $1.06-1.3$ & $1.02-1.24$ & $0.95-1.23$ & $0.95-1.1$ \\
\hline SE & 0.11 & 0.05 & 0.04 & 0.05 & 0.03 \\
\hline SD & 0.24 & 0.1 & 0.095 & 0.11 & 0.067 \\
\hline \multicolumn{6}{|c|}{ Co $\left(\mu g^{-1}\right)$} \\
\hline Range & $0.7-1.0$ & $0.6-1.0$ & $0.6-0.8$ & $0.6-0.7$ & $0.3-0.5$ \\
\hline SE & 0.05 & 0.07 & 0.04 & 0.02 & 0.048 \\
\hline SD & 0.11 & 0.2 & 0.08 & 0.055 & 0.11 \\
\hline \multicolumn{6}{|c|}{$\mathbf{C r}\left(\mu g g^{-1}\right)$} \\
\hline Range & $2-2$ & $2-2$ & $2-2$ & $1-2$ & $1-2$ \\
\hline SE & 0.0 & 0.0 & 0.0 & 0.2 & 0.2 \\
\hline SD & 0.0 & 0.0 & 0.0 & 0.45 & 0.44 \\
\hline \multicolumn{6}{|c|}{$\mathbf{F e}\left(\mu g g^{-1}\right)$} \\
\hline Range & $640-740$ & $640-690$ & $610-690$ & $610-640$ & $540-600$ \\
\hline SE & 19.3 & 9.7 & 12.9 & 6.3 & 11.23 \\
\hline SD & 43.24 & 21.7 & 28.8 & 14.1 & 25.1 \\
\hline \multicolumn{6}{|c|}{$\mathbf{N i}\left(\mu g^{-1}\right)$} \\
\hline Range & $0.7-0.9$ & $0.6-0.8$ & $0.5-0.7$ & $0.5-0.6$ & $0.07-0.5$ \\
\hline SE & 0.037 & 0.045 & 0.03 & 0.02 & 0.086 \\
\hline SD & 0.084 & 0.1 & 0.07 & 0.055 & 0.19 \\
\hline \multicolumn{6}{|c|}{$\mathbf{C u}\left(\mu g^{-1}\right)$} \\
\hline Range & $0.74-0.76$ & $0.67-0.75$ & $0.65-0.68$ & $0.62-0.66$ & $0.58-0.64$ \\
\hline $\mathrm{SE}$ & 0.0045 & 0.015 & 0.006 & 0.008 & 0.0097 \\
\hline SD & 0.01 & 0.03 & 0.01 & 0.02 & 0.02 \\
\hline \multicolumn{6}{|c|}{$\operatorname{Mn}\left(\mu g g^{-1}\right)$} \\
\hline Range & $9.3-11.8$ & $8.8-10.4$ & $7.9-10.3$ & $7.6-9.2$ & $6.5-8.9$ \\
\hline SE & 0.48 & 0.34 & 0.5 & 0.32 & 0.4 \\
\hline SD & 1.08 & 0.76 & 1.2 & 0.7 & 0.88 \\
\hline \multicolumn{6}{|c|}{$\mathbf{C d}\left(\mu \operatorname{cg}^{-1}\right)$} \\
\hline Range & $0.06-0.12$ & $0.06-0.11$ & $0.06-0.08$ & $0.05-0.07$ & $0.02-0.05$ \\
\hline SE & 0.01 & 0.0093 & 0.005 & 0.004 & 0.0054 \\
\hline SD & 0.02 & 0.02 & 0.01 & 0.0084 & 0.01 \\
\hline \multicolumn{6}{|c|}{$\mathbf{A l}\left(\mu g^{-1}\right)$} \\
\hline Range & $600-800$ & $600-700$ & $600-600$ & $600-600$ & $500-600$ \\
\hline SE & 37.41 & 20 & 0.0 & 0.0 & 24.5 \\
\hline SD & 83.7 & 44.7 & 0.0 & 0.0 & 54.77 \\
\hline \multicolumn{6}{|c|}{$\mathbf{C a}\left(\mathrm{mgg}^{-1}\right)$} \\
\hline Range & $15-20$ & $12.5-17.5$ & $10-15$ & $10-15$ & $7-15$ \\
\hline SE & 1.22 & 0.93 & 1.2 & 1.1 & 1.5 \\
\hline SD & 2.7 & 2.1 & 2.7 & 2.5 & 3.4 \\
\hline \multicolumn{6}{|c|}{$\operatorname{Mg}\left(\mathrm{mgg}^{-1}\right)$} \\
\hline Range & $27.4-30.4$ & $25.8-30.4$ & $24.3-25.8$ & $22.8-24.3$ & $15.2-24$ \\
\hline SE & 0.6 & 0.84 & 0.37 & 0.35 & 1.7 \\
\hline SD & 1.34 & 1.9 & 0.82 & 0.78 & 3.7 \\
\hline \multicolumn{6}{|c|}{$\mathbf{N a}\left(\mathrm{mgg}^{-1}\right)$} \\
\hline Range & $13.9-25.2$ & $13.6-16.3$ & $13.2-16.5$ & $12.9-15.2$ & $12.4-13.2$ \\
\hline SE & 2.0 & 0.57 & 0.59 & 0.43 & 0.15 \\
\hline SD & 4.48 & 1.3 & 1.32 & 0.43 & 0.34 \\
\hline \multicolumn{6}{|c|}{$\mathbf{K}\left(\mathrm{mgg}^{-1}\right)$} \\
\hline Range & $4.4-4.6$ & $4.3-4.5$ & $4.2-4.5$ & $4-4.3$ & $4-4.2$ \\
\hline SE & 0.04 & 0.05 & 0.05 & 0.05 & 0.05 \\
\hline SD & 0.09 & 0.1 & 0.11 & 0.012 & 0.11 \\
\hline
\end{tabular}




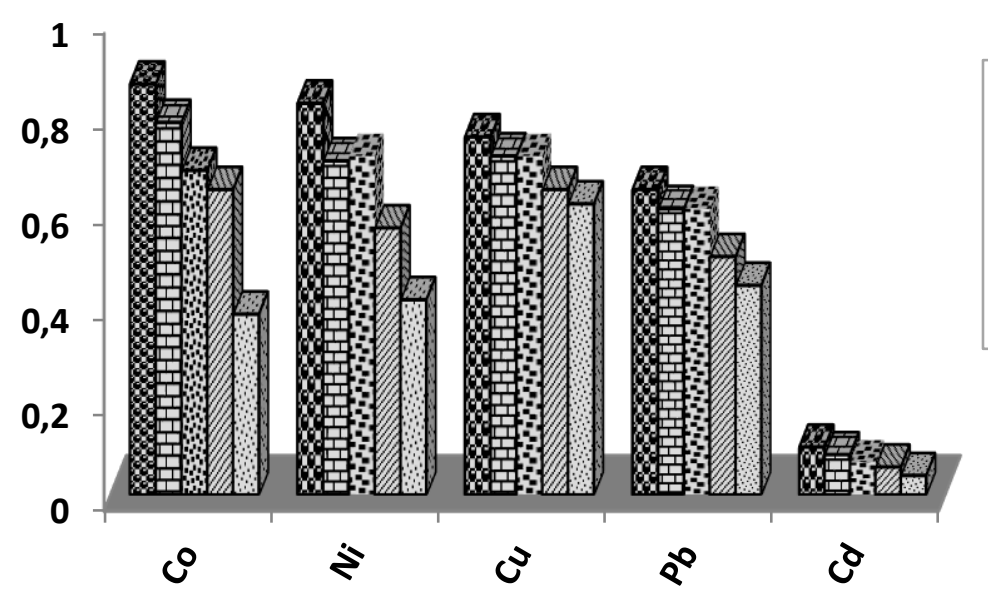

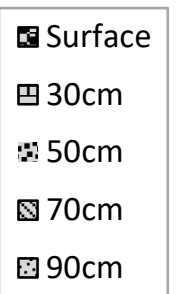

Fig. 2A

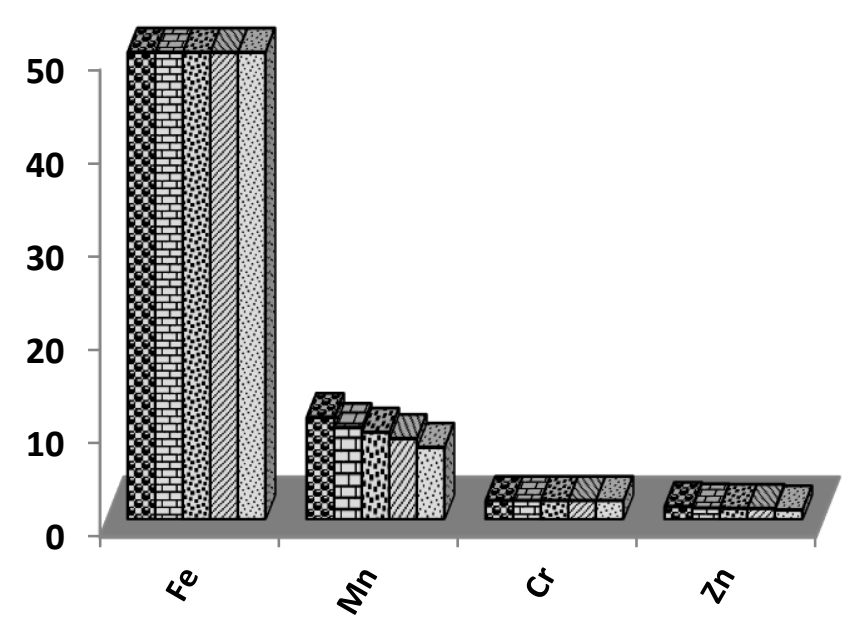

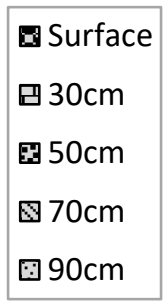

Fig. 2B

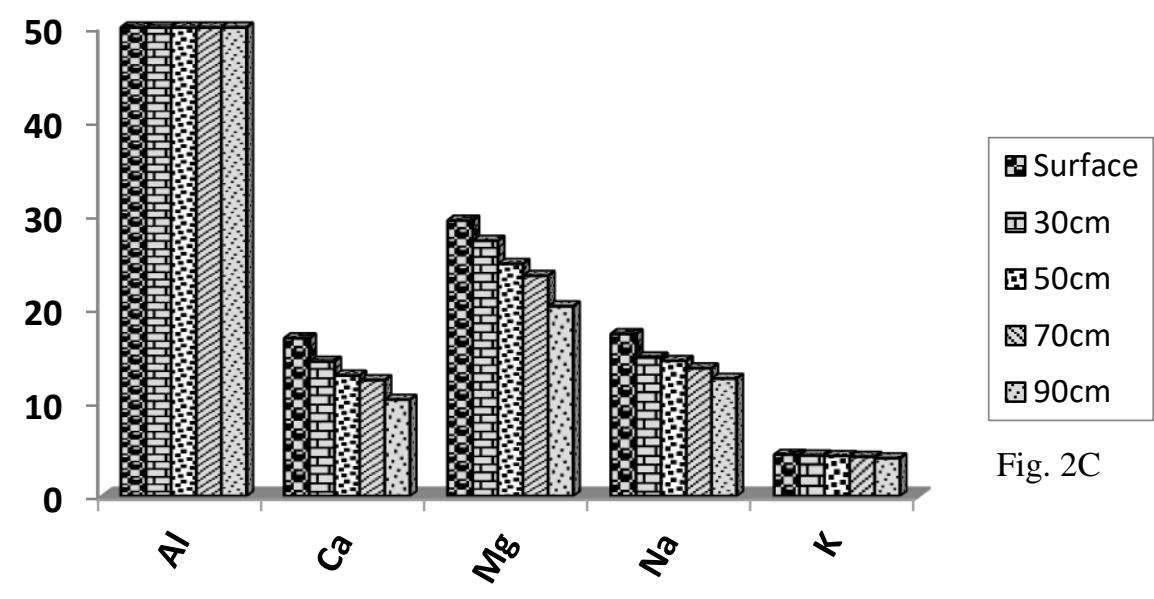

Fig. 2 Distribution of mean metals concentration of core samples in different depths.

We also comparing the data with the Average Shale standard (Turekian and Wedepohl 1961), all measured metals concentrations are lower than the background values (Tab. 3). This is due to much shorter industrial history of the Nile.

The index of geoaccumulation (Tab. 3), Müller (1979) was applied on the results of sediments analysis with respect to shale component (Turekian and Wedepohl 1961) standard in order to obtained 

Fawzy et al.

the origin of metals (lithogenic or anthropogenic) and to quantification of metal pollution in river Nile sediments. Generally, the results obtained in Tab. 3 indicate that the results show that these sediments are uncontaminated with studied metals and unpolluted to moderately polluted with respect to $\mathrm{Ca}$ and $\mathrm{Mg}$ (Tab. 3). This increase in $\mathrm{Ca}$ and $\mathrm{Mg}$ may be to the industrial discharge.

The EFs for measured metals in the surface core samples $(0-30 \mathrm{~cm})$ at different locations are presented in Fig. 3.

Heavy metal concentrations, although relatively higher, remain fairly stable and less than Standard Shall scale (Turekian and Wedepohl 1961), among the different depths in the core especially for Co concentrations at different locations (Tab. 2, 3). The trend of decreasing metal content down the profile is less significant in some cores samples (Tab. 2), the slightly higher levels in the top player especially for $\mathrm{Pb}$ may be due to mixed of sediment layers during deposition and sedimentation stages.

Metals such as $\mathrm{K}, \mathrm{Ca}, \mathrm{Na}$ and $\mathrm{Mg}$ in the total content (Fig. 3b), have EF values significantly greater than unity $(\log \mathrm{EF}>0)$. These metals can therefore be classified as "biophiles" or "anomalously" enriched (Szefer 1998). To a less extent Cd at West-Aswan (Fig. 3a) was generally characterized by EFs close to unity ( $\log \mathrm{EF} \approx 0$ ). This element is therefore dominantly lithogenous in origin.

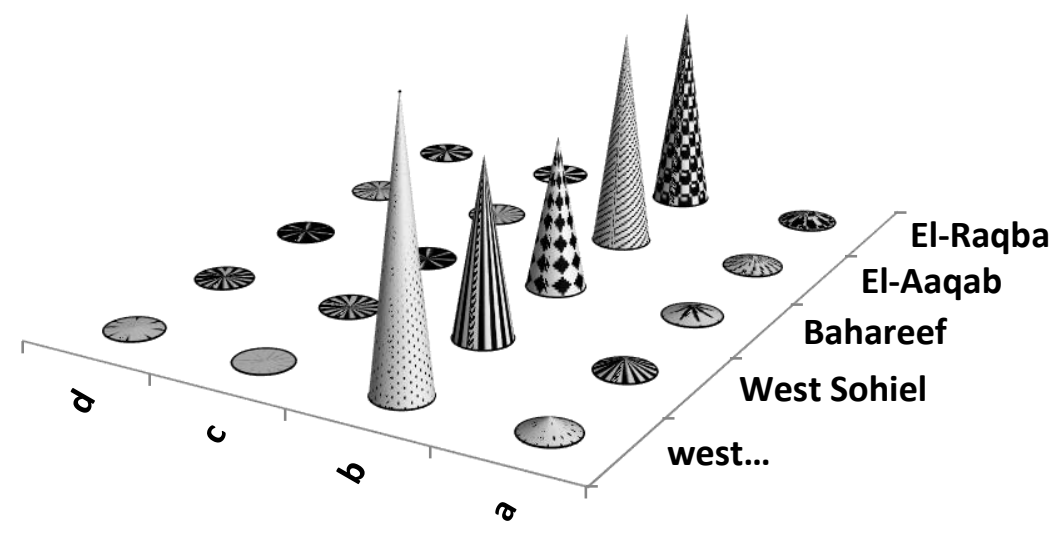

Fig. 3A Enrichment Factors (EFs) for the Studied Metals $(a=P b, b=C d, c=C u, d=N i)$ in the Surface Sediment (0-30) of the River Nile.

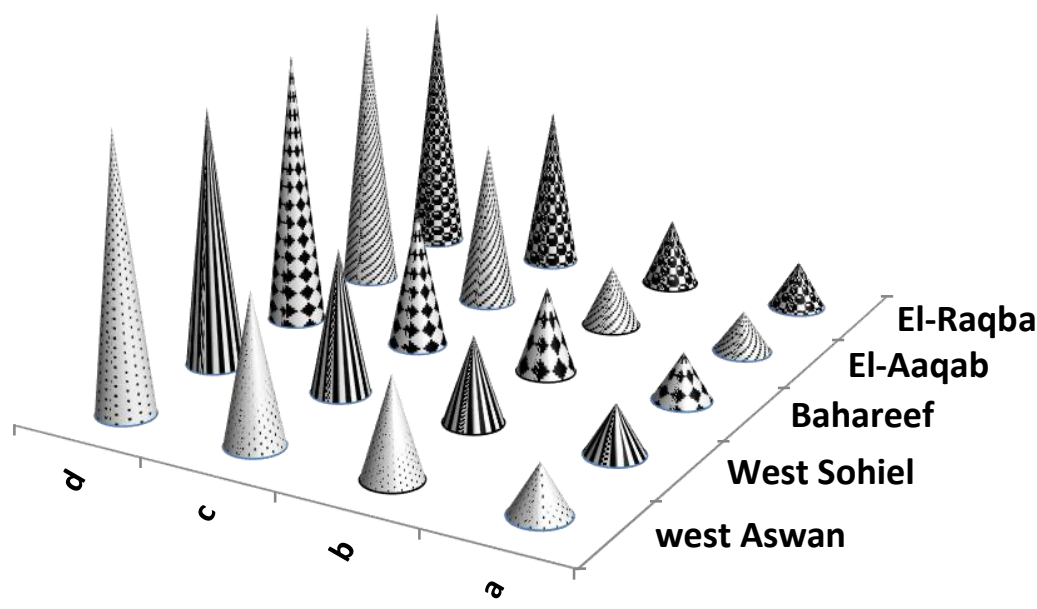

Fig. 3B Enrichment Factors (EFs) for the Studied Metals $(a=K, b=C a, c=N a, d=M g)$ in the Surface Sediment (0-30) of the River Nile. 


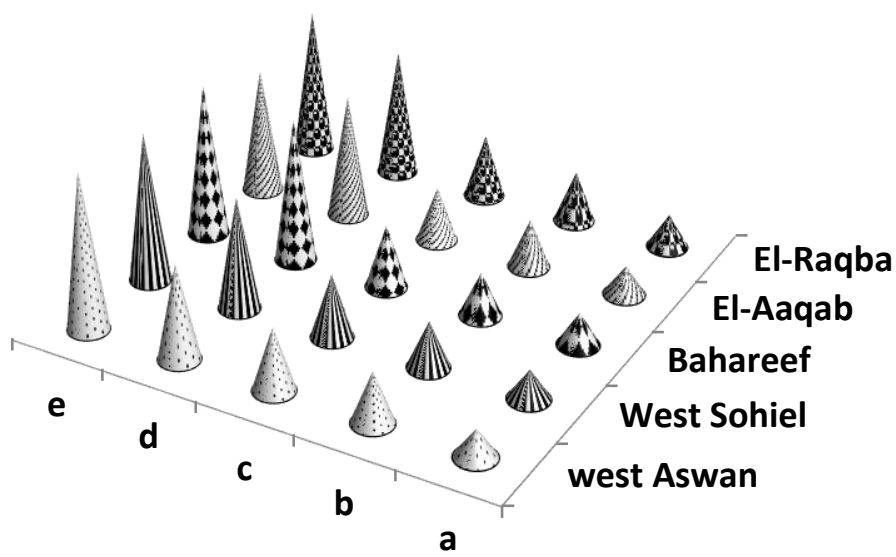

Fig. 3C Enrichment Factors (EFs) for the Studied Metals $(a=M n, b=Z n, c=C r, d=C o, e=F e)$ in the Surface Sediment (0-30) of the River Nile.

$\mathrm{Zn}, \mathrm{Co}, \mathrm{Cr}$, Fe and $\mathrm{Mn}$ (Fig. 3c), in addition to $\mathrm{Ni}, \mathrm{Cu}$, and $\mathrm{Pb}$ (Fig. 3a) have $\mathrm{EF}<1$ (log $\mathrm{EF}<$ 0 ), which indicates that these elements are associated with phases other than aluminosilicates (e.g. $\mathrm{CaCO} 3$, for $\mathrm{Ca}$ ). The processes which lead to the accumulation of metals in the sediments are complexation by organic matter and carbonates (Abu-Rukah and Ghrefat 2001).

Previous research has not conducted a study area, therefore Comparison of some heavy metals in sediment ( $\mathrm{ppm}$ ) with different international guidelines and other studies in the world, refers to low levels significantly from the core sediment concentrations in comparison with the other rivers and standard limits, as shown in Tab. 5.

Tab. 5 Comparison of some heavy metals in sediment (ppm) with different international guidelines and other studies in the world.

\begin{tabular}{cccccccc}
\hline $\begin{array}{c}\text { Sampling site or } \\
\text { Standard }\end{array}$ & Pb & Cd & Cu & Zn & Ni & Cr & Source \\
\hline Nile River at Aswan & 0.5 & 0.07 & 0.6 & 1.1 & 0.6 & 2 & Mean of Present study \\
Seybouse River & 476 & N.A & 9.5 & 1141 & 16.8 & 145 & Louhi et al. 2012 \\
Meghna River & 9.5 & 0.23 & N.A & 79 & 76.1 & 31.7 & Mahmud. et al. 2105 \\
Day River & 109 & 1.27 & 109 & 100 & NA & 102 & Barakat et al. 2012 \\
Yamuna River & 55 & 2.82 & 160 & 366 & 111 & 342 & Singh et al. 2002 \\
Shiqiao River & 96 & 2079 & 100 & 327 & 66 & 133 & Xiao et al. 2013 \\
Guangdong Background & 36 & 0.056 & 17 & 47.3 & 18.2 & 50.5 & Wei et al. 1990 \\
Who 2004 & NA & 0.6 & NA & 123 & 20 & 25 & WHO 2004 \\
USEPA 1999 & 40 & 0.6 & NA & 110 & 16 & 25 & USEPA 1999 \\
CCME 1999 & 35 & 0.6 & NA & 123 & NA & 37.3 & CCME 1999 \\
\hline
\end{tabular}

NA: not available

\section{Statistical analysis}

The statistical analysis of the database resulting from the chemical analysis of metals in the different core samples was performed using SPSS statistics V21 statistical package programs.

Very significant positive correlation was raised between $\mathrm{Cd}, \mathrm{Mn}, \mathrm{Al}, \mathrm{Cu}$ and $\mathrm{Co}$ with $\mathrm{Mg}(\mathrm{r}=$ $1.000,0.965,0.997,0.966$ and 0.948 , respectively) may be attributed to their existence with Mg-bearing minerals especially olivine (Fawzy 2012). Good correlations were found between $\mathrm{Ca}$ and $\mathrm{Fe}(\mathrm{r}=0.968)$ $\& \mathrm{~K}$ and $\mathrm{Pb}(\mathrm{r}=1.000)$ in different sectors of core samples, which indicates that accumulation of these 
metals have a similar transport mechanism. Strong positive correlation coefficient value $(r=0.968)$ is raised between lead and iron. This supported by the fact that $\mathrm{Pb}$ is strongly associated with ferromanganese minerals.

Strong negative correlations are observed in the different core samples between the extractable $\mathrm{Ca}$ content and the other metals such as $\mathrm{Al}, \mathrm{Co}, \mathrm{Mg}, \mathrm{Mn}$ and $\mathrm{Na}(\mathrm{r}=-1.000,-1.000,-0.997,-0.993$ and -0.969 , respectively). These findings may be related to the presence of Ca-bearing silicate minerals with low metal contents.

No observed correlations between $\mathrm{pH}$ and $\mathrm{Cr}, \mathrm{Cd}$, and $\mathrm{Zn}$ indicate that the adsorption of these metals is weakly pH-dependent (Soltan et al. 2011). Appearance of negative significant correlation coefficient values between $\mathrm{pH}$-value and the metal content of $\mathrm{Fe}(\mathrm{r}=-0.922), \mathrm{K}(\mathrm{r}=-0.966), \mathrm{Ca}$ $(\mathrm{r}=-0.966), \mathrm{Cu}(\mathrm{r}=-0.927), \mathrm{Pb}(\mathrm{r}=-1.000)$ and $\mathrm{Ni}(\mathrm{r}=-1.000)$ These correlations indicate similar adsorption behavior for these metals, whereas, high adsorption capacity were obtained at $\mathrm{pH}<6$, but at high $\mathrm{pH}$-value the hydrolysis and precipitation of metals were occurred.

On the other hand, good positive correlation coefficients values were recorded between $\mathrm{Co}(\mathrm{r}=0.964), \mathrm{Al}(\mathrm{r}=0.966), \mathrm{Mg}(\mathrm{r}=0.968), \mathrm{Mn}(\mathrm{r}=0.951)$ and $\mathrm{pH}$ value.

\section{Conclusion}

Generally, all measured metals decrease with increasing depth. These features reflect the contamination from the recent rapid industrial development and urbanization on the sides of river Nile. The sources of heavy metals in the sediments vary for each element, but include the weathering of bedrock, waste discharge from fishery boats and tourist ships. The interrelationships between physicochemical processes, biological and anthropogenic activities affect the spatial distribution of heavy elements in river Nile.

The obtained results also shows that the levels of sediment contamination within the safe side according to different background values (e.g. standard shale). On the other hand, although the concentrations of the heavy elements in the Nile sediments indicate no pronounced threat to public health at the moment, this situation may change, where the element concentrations in the sediments increase with time.. On the other hand, the study points out to the need to preserve waterways free from the pollution and the need for wastes treatment whatever their source, and the urgent need to implement the laws of Nile River protection from pollutions accurately and strict, in addition to, the continuous survey of the Nile sediments to see changes in the concentrations of elements to avoid causes aphid.

\section{References}

Abu-Rukah Y, Ghrefat HA (2001) Assessment of the anthropogenic influx of metallic pollutants in Yarmouk river, Jordan. Environmental Geology 40 (6): 683 - 692.

Andersen MK, Rasmussen KR, Hansen HCB, Strobel BW (2002) Distribution and fractionation of heavy metals in pairs of arable and afforested soils in Denmark. Journal European of soil science 53: 491-502.

APHA (1992) American Public Health Association: Standard methods for the examination of water and wastewater, 18th edition (Washington, DC : APHA).

Balkis N, Cagatay MN ( 2001) Factors controlling metal distributions in the surface sediments of the Erdek Bay, Sea of Marmara, Turkey. Environment International 27: 1 - 13.

Barakat A, Baghdadi M.E, Rais J, Nadem, S (2012) Assessment of heavy metal in surface sediments of Day River at Beni-Mellal region, Morocco. Research Journal of Environmental and Earth 4: 797806.

Belzile N, Lecomte P, Tessier A (1989) Testing readsorption of trace elements during partial chemical extractions of bottom sediments. Environmental Science Technology 23: 1015-1020.

Bernasconi MP, Stanley DI. Journal of Coastal Research . 10, 2, 440.61 (1994). 
Fawzy et al.

Bing, H.J., Wu, Y.H., Zhou, J., Li, R., Wang, J.P., 2016. Historical trends of anthropogenic metals in Eastern Tibetan Plateau as reconstructed from alpine lake sediments over the last century. Chemosphere 148, 211-219.

Calmano W, Hong J, Forstner U (1993) Binding and mobilization of heavy metals in contaminated sediments affected by pH redox potential. Water Science Technology 28 (8-9): $223-35$.

Carretero M.I (2002) Clay minerals and their beneficial effects upon human health. A review Applied Clay Science 21:155- 63 .

CCME (1999) Canadian water quality guidelines for protection of aquatic life. Canadian Water Quality Index 1.0, Technical Report, Canadian Environmental Quality Guidelines.

Chatteriee M, Silva EV, Sarkar SK, Sella SM, Bhattacharya A, Satpathy KK, Prasad MVR, Chakraborty S, Bhattacharya BD (2007) Distribution and possible source of trace elements in the sediment cores of a tropical macrotidal estuary and their ecotoxicological significance. Environmental International 33 (3): 346-356.

Chen H, Chen R, Teng Y, Wu J (2016) Contamination characteristics, ecological risk and source identification of trace metals in sediments of the Le'an River (China). Ecotoxicology and Environmental Safety 125: 85-92.

Chen HY, Teng YG, Li J, Wu J, Wang JS (2016) Source apportionment of trace metals in river sediments: a comparison of three methods. Environmental Pollution 211: 28-37.

Chen M, Ding S, Zhang L, Li Y, Sun Q, Zhang C (2017) An investigation of the effects of elevated phosphorus in water on the release of heavy metals in sediments at a high resolution. Science of the Total Environment $575: 330-337$.

El Azhari A, Rhoujjati A, EL Hachimi M (2016) Assessment of heavy metals and arsenic contamination in the sediments of the Moulouya River and the Hassan II Dam downstream of the abandoned mine Zeïda (High Moulouya, Morocco). Journal of African Earth Sciences 119: 279-288.

Fawzy EM(2000) Physico-chemical studies on the speciation of heavy elements in the River Nile sediments. M.Sc. Thesis, Faculty of Science, South Valley University, Egypt.

Fawzy EM, Ahmed MM, Soltan ME, Gamal TA (2012) Spatial and seasonal variations in depth profile of heavy metals in some sediments from Red Sea Islands protectorates (Egypt) and the effect of grain size on immobilization of these metals. Toxicological and Environmental Chemistry 94(1): 1053-1074.

Franca S, Vinagre C, Cacador I, Cabral H N (2005) Heavy metal concentrations in sediment, invertebrates and fish in three salt marsh areas subjected to different pollution loads in the Tagus Estuary ( Portugal ). Marine Pollution Bulletin 50: 993-1018.

Fu J, Zhao C, Luo Y, Liu C, Kyzas G Z, Luo Y, Zhao D, An S, Zhu H (2014) Heavy metals in surface sediments of the Jialu River, China: Their relations to environmental factors. Journal of Hazardous Materials 270: 102-109.

Gao X, Zhou F, Chen CT ( 2014 ). Pollution status of the Bohai Sea: An overview of the environmental quality assessment related trace metals. Environment International 62: 12-30.

Gismera M J, Lacal J, da Silva P, García R, Sevill M T (2004) Study of metal fractionation in river sediments. A comparison between kinetic and sequential extraction procedures. Environmental Pollution 127: 175-182.

Gu YG,Wang XN, Lin Q, Du FY, Ning JJ, Li YF (2016) Fuzzy comprehensive assessment of heavy metals and $\mathrm{Pb}$ isotopic signature in surface sediments from a bay under serious anthropogenic influences: Daya Bay, China. Ecotoxicology Environmental Safety 126: 38-44.

Gu YG, Lin Q (2016) Trace metals in a sediment core from the largest mariculture base of theeastern Guangdong coast, South China: Vertical distribution, speciation, and biological risk. Marine Pollution Bulletin 113: 520-525.

Han LF, Gao B, Wei X, Gao L, Xu DY, Sun K (2015). The characteristic of Pb isotopic compositions in different chemical fractions in sediments from Three Gorges Reservoir, China. Environmental Pollution 206: 627-635.

Harikumar PS, Nasir UP (2010) Ecotoxicological impact assessment of heavy metals in core sediments of a tropical estuary. Ecotoxicology Environmental Safety 73: 1742-1747.

Hernandez-Avila M, Gonzalez-Cossio T, Peterson KE, Palazuelos E, Hu H ( 2003 ) Dietary calcium supplements to lower blood lead levels in lactating women: a randomized placebo controlled trial. Epidemiology 14(2): 206-212. 
Fawzy et al.

Janaki D, Jonathan MP, Srinivasalu S, Armstrong JS, Mohan SP, Ram-Mohan V (2007) Trace metal enrichments in core sediments in Muthupet mangroves, SE coast of India: Application of acid leachable technique. Environmental Pollution 145 (1): 245-257.

Kalantzi I, Shimmield TM, Pergantis SA, Papageorgiou N, Black KD, Karakassis I (2013) Heavy metals, trace elements and sediment geochemistry at four Mediterranean fish farms. Science of the Total Environment 444: 128-137.

Kersten M, Smedes F (2002) Normalization procedures for sediment contaminants in spatial and temporal trend monitoring. Journal of Environmental Monitoring 4: 109- 115.

Koh TS, Judson GT (1986) Trace elements in sheep grazing near a lead-zinc smelting complex at Port Pirie South Australia. Bulletin of Environmental Contamination and Toxicology 37: 87-95.

Krishnamurti GSR, Huang PM, Van Rees KCJ, Kozzak LM, Rostad HPW (1995) Speciation of particulate-bound cadmium of soils and its bioavailability. Analyst 120: 659-665.

Landre A L, Winter G J, Helm P, Hiriart-Baer V, Young J (2011) Metals in Lake Simcoe sediments and tributaries: Do recent trends indicate changing sources?. Journal of Great Lakes Research 37 (3): 124-131.

Li F, Huang J, Zeng G, Yuan X, Li X., Liang J, Wang X, Tang X, Bai B (2013) Spatial risk assessment and sources identification of heavy metals in surface sediments from the Dongting Lake, Middle China. Journal of Geochemical Exploration 132: 75-83.

Li XD, Coles B J, M. Rammsey H, Thornton I (1995) Sequential extraction of soils for multielement analysis by IOP-AES. Chemical Geology 124: 109-123.

Li X, Wai OWH, Li YS, Coles B J, Ramsey M H, Thornton I (2000) Heavy metal distribution in sediment profiles of the Pearl river estuary, South China. Applied Geochemistry 15:567-581.

Lin CW (2002) Mapping soil lead and remediation needs in contaminated soils. Environmental geochemistry and health 24: 23-33.

Louhi A, Hammadi A, Achouri M (2012) Determination of some heavymetal pollutantsin sediments of the Seybouse River in Annaba, Algeria. Air Soil Water Research 5: 91-101.

Mahmud H, Mirza ATM, Tanvir R, Badhan S, Abdul Kadir IK (2015) Status of Heavy Metals in Water and Sediment of the Meghna River, Bangladesh. American Journal of Environmental Sciences 11 (6): 427-439.

Merry RH, Tiller KG, Alston AM (1983) Accumulation of copper, lead and arsenic in some Australian orchard soils. Austrian journal of soil research 21: 549- 561.

Middleton R, Grant A (1990) Heavy metals in the Humber estuary: Scrobicularia clay as a preindustrial datum. Proceedings of the Yorkshire geological society 48:75 - 80 .

Moalla SMN, Soltan ME, Rashed MN, Fawzy E.M (2006) Evaluation of dilute hydrochloric acid and acid ammonium oxalate as extractants for some heavy metals from Nile River sediments. Ecology and Chemistry 22(4): 313-327.

Muller G (1969) Index of geoaccumulation in sediments of the Rhine river. The Journal of geology 2(3): 108-118.

Müller G (1979) Schwermetalle in den sedimenten des Rheins-Verănderungen seit 1971. Umschau 79(24): 778-783.

Mulligan CN, Yong RN, Gibbs BF (2001) Remediation technologies for metal contaminated soils and groundwater: an evaluation. Engineering Geology 60: 193-207.

Oldfielda F, Asiolib A, Accorsi C A, Mercuri AM, Juggins S, Langone L, Rolph T, Trincardi F, Wolff G, Gibbs Z et al. (2003) A high resolution late Holocene palaeo environmental record from the central Adriatic Sea. Quaternary Science Reviews 22: 319-342.

Shi Q, Thomas L, Peter R, Zhou D, Jan H.. 2010. Geochemical sources, deposition and enrichment of heavy metals in short sediment cores from the Pearl River Estuary, Southern China. Journal of Marine System 82: 28-42.

Shokrzadeh M, Saeedi SS (2010) The study of heavy metals ( zinc, lead, cadmium, and chromium ) in sediment sampled from Gorgan coast ( Iran ), spring 2008. Toxicological and Environmental Chemistry 92(1): 67-69.

Singh M, Müller G, Singh IB (2002) Heavy metals in freshly deposited stream sediments of rivers associated with urbanisation of the Ganga Plain, India. Water Air Soil Pollution 141: 35-54.

Soltan M.E (2006) Remobilization of selected metal ions from Nile sediment( Egypt ) according to sequential extraction and metal - EDTA complex. Ecology and Chemistry 22(5): 359-378. 
Soltan ME, Moalla SMN, Rashed MN, Fawzy EM (2011) Internal metal distribution in sediment - pore water - water systems of bights at Nasser lake, EGYPT . Journal of Environmental Systems 33(2): 179-215.

Szefer P, Glosby GP, Szefer K, Penopkowiak J, Kallszan R (1996) Heavy metals pollution in surficial sediments from the southern Baltic sea of Poland. Journal of Environmental Science and Health 31A: 2723-2754.

Szefer P (1998) Distribution and behaviour of selected heavy metals and other elements in various components of the Southern Baltic ecosystem. Applied Geochemistry 13: 287-292.

Tessier A, Campbell PGC, Bisson M (1979) Sequential extraction procedure for the speciation of particulate trace metals. Analytical Chemistry 5: 844-851.

Turekian KK, Wedepohl KH (1961) Distribution of the elements in some major units of the Earth Crust. Geological Society of America Bulletin 72: 175 - 192 (1961).

USEPA (1999) Screening level ecological risk assessment protocol for hazardous waste combustion facilities, Appendix E: Toxicity reference values. United States Environmental Protection Agency

Vallius H (2014) Heavy metal concentrations in sediment cores from the northern Baltic Sea: declines over the last two decades. Marine Pollution Bulletin 79: 359-364.

Veerasingam S, Vethamony P, Mani MR, Fernandes B (2015). Depositional record of trace metals and degree of contamination in core sediments from the Mandovi estuarine mangrove ecosystem, west coast of India. Marine Pollution Bulletin 91: 362-367.

Vreca P, Dolenec T (2005) Geochemical estimation of copper contamination in healing mud from Makirina Bay, central Adriatic. Environment International 31: 53- 61.

Wang C, Liu S, Zhao Q, Deng L, Dong S (2012) Spatial variation and contamination assessment of heavy metals in sediments in the Manwan Reservoir, Lancang River. Ecotoxicology and Environmental Safety 82: 32-39.

Wang Y, Yang L, Kong L, Liu E, Wang L, Zhu J (2015) Spatial distribution, ecological risk assessment and source identification for heavy metals in surface sediments from Dongping Lake, Shandong, East China. CATENA 125: 200-205.

Wang Z.H, Feng J, Jiang T, Gu YG (2013). Assessment of metal contamination in surface sediments from Zhelin Bay, the South China Sea. Marine Pollution Bulletin 76: 383-388.

Watson DH (2001) Food chemical Safety Watson D.H. (Ed), CRC Press Boca Raton FL, vol. 1: 1-12.

Wei FS, Chen JS, Wu YY, Zheng CJ, Jiang DZ (1990) Background Contents of Elements in China Soils. Publishing House of Chinese Environmental Sciences, Beijing (in Chinese).

Whelan III T, Espinoza J, Villarreal X, CottaGoma M (2005) Trace metal partitioning in Thalassia testudinum and sediments in the Lower Laguna Madre, Texas. Environment International 31: 1524.

WHO (2004) Guidelines for Drinking Water Quality. $3^{\text {rd }}$ Edn., World Health Organization, pp: 515.

Winkels HJ, Vink JPM, Beurskens JE (1993) Distribution and geochronology of priority pollutants in a large sedimentation area, river Rhine the Netherlands. Applied Geochemistry 52: 95-101.

Xiao R, Bai J, Huang L, Zhang H, Cui B, Liu X (2013) Distribution and pollution, toxicity and risk assessment of heavy metals in sediments from urban and rural rivers of the Pearl River delta in southern China. Ecotoxicology 22: 1564-1575

Yu K, Tsai L, Chen S H, Ho ST (2001) Chemical binding of heavy metals in Anoxic River sediments. Water Research 35 (17): 4086 - 4094. 